\title{
Jan Vermant follows Dimitrios Vlassopoulos as European editor of Rheologica Acta
}

\author{
H. Henning Winter • Marion Hertel
}

Published online: 23 December 2011

(C) Springer-Verlag 2011

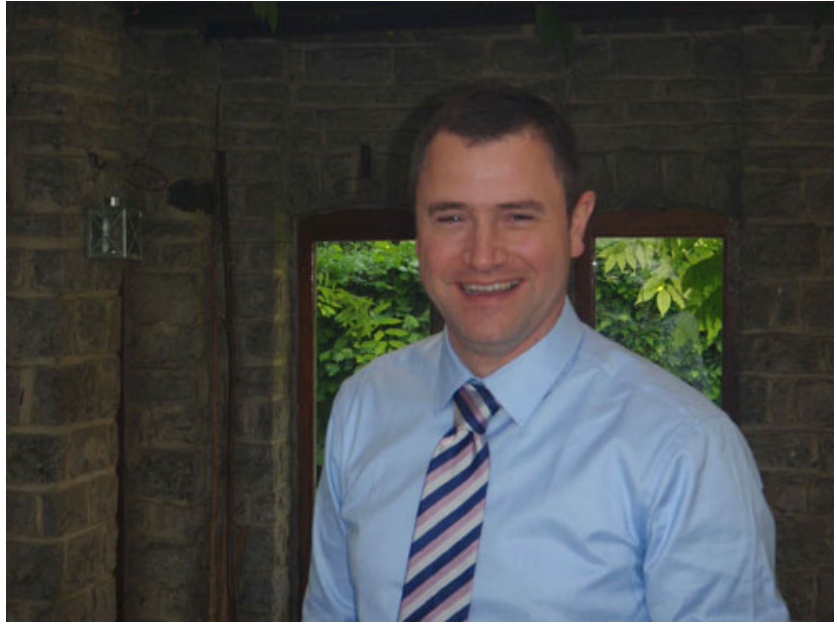

When Rheologica Acta became the Official Journal of the European Society of Rheology (ESR) in 2006, it was decided that Rheologica Acta will add a second editor, the so-called European Editor. Both editors share equal responsibilities in their service to the rheology community. However, as additional function, the European Editor serves as liaison between Rheologica Acta and the ESR.

\section{H. H. Winter $(\bowtie)$}

Department of Chemical Engineering,

University of Massachusetts, Amherst, MA 01003, USA

e-mail:winter@ecs.umass.edu

\section{Hertel}

Chemistry Editorial, Springer, Tiergartenstrasse 17,

69121 Heidelberg, Germany

e-mail: marion.hertel@springer.com
The first European Editor, Dimitrios Vlassopoulos, has recently stepped down after five active years. In many ways, Rheologica Acta has become a better journal through his leadership and dedication. Dimitrios strengthened the ties of Rheologica Acta to the ESR and to many rheologists worldwide. These are enduring contributions which will last. Dimitrios will continue to work with us as a member of the Rheologica Acta editorial board. We probably can speak for the entire rheological community to express a major thank you to Dimitrios for his outstanding service as editor.

As of September 2011, the new "European Editor" of Rheologica Acta is Jan Vermant. An international search committee, appointed by ESR, had contemplated a large number of possible candidates and suggested Jan Vermant to become the second "European Editor". Following this suggestion, Jan Vermant was appointed by Springer Verlag.

Jan Vermant has made significant contributions to rheology. He earned his doctoral degree in Chemical Engineering at Katholic University (K.U.) Leuven in 1996 for a study on liquid crystalline polymers. After postdoctoral fellowships at Stanford University, at the Ecole des Mines in Sophia Antipolis, and at the Centre de Recherche Paul Pascal, URA, CNRS, Jan joined the faculty at K.U. Leuven in 2000. Jan is currently a full professor of chemical engineering and the departmental chairperson. His research awards include a Dupont Young Faculty Award (2002-2004), the FWO-ExxonMobil Chemical European Science \& Engineering Award (2007), and the Journal of Rheology Publication Award for 2009. He is a Fellow of the Royal Society of Chemistry since 2010. Jan's specific research interests include the link between structure and rheology in colloidal suspensions and soft matter composite systems, directed 
self-assembly of colloidal particles, complex fluid-fluid interfaces and active' colloidal systems and bacteria. In a recurring theme, he is trying to connect the microscopic world with macroscopic phenomena.

The submission of papers to Rheologica Acta is not affected. The two editors, H. Henning Winter and
Jan Vermant, will alternate in taking responsibility in guiding your paper through the review process. Please continue to submit your papers through http://mc. manuscriptcentral.com/ra/.

We invite the global community of rheologists to join us in a warm welcome for Jan Vermant as editor. 